\title{
Harold James, Martin Müller (dir.), Georg Solmssen - ein deutscher Bankier. Briefe aus einem halben Jahrhundert 1900-1956
}

München : C.H. Beck, (Schriftenreihe zur Zeitschrift für

Unternehmensgeschichte, 25), 2012, 642 p., $68 €$

Rachid L'Aoufir

\section{OpenEdition}

Journals

Édition électronique

URL : http://journals.openedition.org/ifha/7719

DOI : 10.4000/ifha. 7719

ISSN : 2198-8943

Éditeur

IFRA - Institut franco-allemand (sciences historiques et sociales)

Référence électronique

Rachid L'Aoufir, « Harold James, Martin Müller (dir.), Georg Solmssen - ein deutscher Bankier. Briefe aus einem halben Jahrhundert 1900-7956», Revue de I'IFHA [En ligne], Date de recension, mis en ligne le 13 décembre 2013, consulté le 22 septembre 2020. URL : http://journals.openedition.org/ifha/7719 DOl : https://doi.org/10.4000/ifha.7719

Ce document a été généré automatiquement le 22 septembre 2020.

(CIFHA 


\title{
Harold James, Martin Müller (dir.), Georg Solmssen - ein deutscher Bankier. Briefe aus einem halben Jahrhundert 1900-1956
}

\author{
München : C.H. Beck, (Schriftenreihe zur Zeitschrift für \\ Unternehmensgeschichte, 25), 2012, 642 p., $68 €$
}

Rachid L'Aoufir

Cette édition soignée de la correspondance de Georg Solmssen (1869-1957) s'inscrit dans la continuité des travaux d'Harold James et de Martin Müller sur l'histoire de la Deutsche Bank. Georg Solmssen fut membre puis président du conseil d'administration de la Deutsche Bank und Disconto Gesellschaft de 1929 à 1934 avant d'en devenir membre du conseil de surveillance de 1935 à 1938. L'ouvrage est divisé en trois parties: l'introduction, les lettres, les annexes. L'introduction contient une esquisse biographique de quarante-deux pages rédigée par Harold James, ainsi qu'une note éditoriale. L'ouvrage présente 381 lettres qui couvrent surtout la période 1920-1930, 250 sont de Solmssen et 131 de ses correspondants, essentiellement des dirigeants de banques et de sociétés industrielles comme Fritz Thyssen et Gustav Krupp von Bohlen und Halbach. Les annexes de quatre-vingt-dix pages contiennent un registre instructif des personnes et des lieux, une bibliographie des écrits publiés par le banquier et une liste des quatre-vingt sociétés dans lesquelles il a été membre du conseil de surveillance.

Harold James rappelle que cette position éminente a permis à Solmssen de participer, pendant la période weimarienne, à la restructuration de l'industrie allemande et aux débats publics sur l'économie politique. Dans un deuxième temps il montre comment le banquier a été progressivement écarté de ces mandats après 1933, puis comment ses attaches à l'Allemagne se sont défaites, de la vente forcée de ses biens immobiliers en passant par l'installation de ses enfants aux Etats-Unis et l'interruption du versement de sa pension à son renoncement à la nationalité allemande pour la Suisse. 
Même si l'état des archives n'a pas toujours permis de reconstituer toutes les activités $\mathrm{du}$ banquier, le lecteur le voit agir dans ses diverses fonctions commerciales et publiques. Il gère la fusion entre la Deutsche Bank et la Disconto Gesellschaft, arbitre entre les directeurs rivaux de Cologne et de Berlin, négocie avec les ministères le sauvetage de firmes comme la Hapag et la Lloyd, participe à des comités de la banque centrale. Solmssen calcule des prises de participations dans le capital de sociétés pour assurer des droits de vote à sa banque, s'assure que les mesures de restructuration industrielle stabilisent les cours des actions qu'elle détient, pèse sur les quotes-parts dans les crédits consortiaux, place ses pions dans les conseils de surveillance dont une des missions est d'écouler sur le marché les titres commerciaux mis au point par les banques pour financer l'industrie.

En tant qu'auteur de lettres, de longues notes explicatives dans ses dossiers, de mémoires, de discours et d'articles de journaux, Solmssen était encore ancré dans une culture de l'écrit bien qu'il vécût à l'ère du téléphone et du télégraphe. Sa formation de juriste et le souci de la preuve marqua sa culture d'entreprise soucieuse d'équilibrer l'intérêt privé et l'intérêt public, ce qui explique sa rigueur. Sa conversion au protestantisme et le changement de son nom Salomosohn en Solmssen au début de sa carrière de banquier en 1900 n'auront pas empêché la bêtise des appareils politique et administratif d'en faire un exclu puis un exilé suisse. Au total, en tant que genre, le courrier professionnel n'a ni la dramaturgie ni la qualité littéraire des journaux intimes de l'époque, par exemple de Viktor Klemperer ou de Willy Cohn. Pour mieux comprendre les enjeux commerciaux et financiers exprimés dans ces lettres, il faut se reporter aux ouvrages récents qui analysent le rôle des banques durant la période considérée. Se trouvera-t-il un historien qui saura écrire la vie de Solmssen en restituant plus précisément ce cadre dramatique?

\section{INDEX}

Index chronologique : Neuere und Neueste Geschichte

Thèmes : Wirtschaftsgeschichte

\section{AUTEUR \\ RACHID L'AOUFIR}

Berlin 